\title{
Egg quality characteristics of three strains of layer chickens, a principal component analysis
}

\author{
I. Udeh*, O. P. Akporhuarho, and E. F. Matthew \\ Department of Animal Science, Delta State University, Asaba Campus, Asaba, Nigeria \\ *Corresponding Email: udehifeanyichukwu@ymail.com \\ Received June 30, 2021; Accepted September 29, 2021
}

\begin{abstract}
The aim of this study was to compare the external and internal egg quality of three layer strains namely Bovan Nera, ISA Brown and FUNAAB Alpha. One hundred and fifty eggs sampled from 120 birds per strain from 35 to 45 weeks of age were used for the study. Data collected were analysed using one way analysis of variance in a completely randomized design. ISA Brown had significantly $(\mathrm{P}<0.01)$ the heaviest eggs on the average at 45 weeks, followed by Bovan Nera and FUNAAB Alpha. The egg quality characteristics of Bovan Nera and ISA Brown were similar but significantly $(\mathrm{P}<0.05)$ superior to FUNAAB Alpha in egg width, egg volume, egg surface area and albumen weight. FUNAAB Alpha was significantly $(\mathrm{P}<0.05)$ the most superior in yolk weight only. Three principal components (PC1, PC2 and PC3) were produced from each strain after principal component analysis and varimax rotation. Estimation of breeding values based on the three principal components could be used for the selection and improvement of egg quality variables in each strain instead of isolated traits.
\end{abstract}

Keywords: Communalities, Correlations, Eigen value, Loadings, Selection

\section{INTRODUCTION}

Egg production in Nigeria depends on commercial hybrids imported into the country whose performance depends on genotype by environment interaction. Egg quality is composed of those characteristics of an egg that affect its acceptability by the consumers (Hanusova et al., 2015). The external and internal qualities of an egg are mainly affected by the age and genotype of the birds (Monira et al., 2003). External quality is composed of eggshell colour, egg shape index, eggshell thickness and eggshell strength, while internal quality refers to albumen height, egg yolk colour and haugh unit (Liu et al.,
2018). Bovan Nera and ISA Brown are among the commercial strains of egg type chickens reared by farmers in southern Nigeria. They are known to be very efficient in egg production and lay brown eggs. On the other hand, FUNAAB Alpha is an indigenous breed of egg type chicken bred at Federal University of Agriculture Abeokuta, Nigeria. They lay white shelled eggs. The egg quality variables of each strain of chicken could be correlated to each other to various degrees (Bjorklund, 2019). This makes it difficult to interpret as a correlated group. This is usually overcome by principal component analysis (PCA), a mathematical procedure that uses orthogonal transformations of the covariance ma- 
trix with the aim of reducing a set of correlated variables to a smaller number of non-correlated variables called principal components, with minimal loss of information from the covariance matrix (Hair et al., 2009 cited by Venturini et al., 2013). A number of studies reported the use of PCA to define the underlying components of egg quality characteristics of chickens. For example, Goto et al. (2015) reported that PCA on 22 egg quality trait of Japanese extremely long tailed chickens revealed five principal components accounting for $79.70 \%$ of the total variance. Abdullah and Shaker (2018) reported that two components were extracted from the egg quality parameters of each of the four lines of Kurdish local chicken explaining $82.71 \%, 80.45 \%, 84.09 \%$ and $76.40 \%$ of the total variance respectively. Babajani et al. (2018) reported that the use of PCA for internal egg quality and performance traits of native hens can reduce computing cost and time of genetic evaluation of multiple traits.

The objective of this study was to compare the external and internal egg qualities of two commercial strains of egg type chicken with an improved indigenous breed and determine the core components underlying egg quality characteristics in each strain of chicken using PCA.

\section{MATERIALS AND METHODS}

\section{Experimental Site}

The study was conducted at the poultry unit of the teaching and research farm of the Department of Animal Science, Faculty of Agriculture, Delta State University, Asaba Campus. The study area is located at latitude $6^{0} 12^{\mathrm{I}} \mathrm{N}$ and longitude $6^{0} 45^{\mathrm{I}} \mathrm{E}$ with an annual rainfall that ranges from 1800 to $3000 \mathrm{~mm}$.

\section{Experimental Birds}

A total of 360 layer chickens comprising of 120 hens each of Bovan Nera, ISA Brown and FUNAAB Alpha were used for the study. The three strains of layer chickens were acquired at 18 weeks of age from Abeokuta, Ondo State, Nigeria. Each strain of layer chicken was maintained in four replicate pens of thirty birds each for the purpose of management and egg collection.

\section{Management of the Experimental Birds:}

The three strains of layer chickens were managed in deep litter floor pens and fed ad libitum commercial layer mash containing 17\% crude protein, $2676 \mathrm{Kcal} \mathrm{ME} / \mathrm{kg}$ and $3.00 \%$ calcium. Clean drinking water was made available free choice. All other routine management procedures such as cleaning of the poultry house, washing of drinkers and feeders were observed. All the necessary vaccines and drugs were administered at the appropriate ages. Egg collection was done three times daily.

\section{Data Collection}

Egg quality measurements were taken on Tuesday of every week from 35-45 weeks. Twelve (12) eggs were sampled from the egg production of each strain on the day of measurements and used for the quality study. The following external and internal egg quality characteristics were measured: Egg weight: This was measured using a sensitive digital weighing balance with accuracy of $0.001 \mathrm{~g}$. Egg length and width were measured in $\mathrm{cm}$ using a vernier calliper. Egg volume was calculated using the following formula: $\mathrm{V}=(0.6057-0.00018 \mathrm{~B}) \mathrm{LB}^{2}$ where $\mathrm{V}=$ egg volume (cm3), $\mathrm{L}=$ egg length and $\mathrm{B}=$ maximum breadth. Egg shell weight: Intact egg is broken and the content poured into a container. The egg shell was washed with water and left to dry. The eggshell weight was then taken using sensitive electronic weighing balance. Egg surface area: Egg surface area $(\mathrm{cm} 2)$ was calculated using the following expression: $\mathrm{SA}(\mathrm{cm} 2)=$ (3.155 - 0.0136L + 0.0115B) $\mathrm{LB}^{2}$, where $\mathrm{L}=$ egg length and $\mathrm{B}=$ egg weight. Yolk weight and $\mathrm{Al}-$ bumen weight: The yolk and albumen were carefully separated and weighed using a sensitive electronic weighing balance as described by Ahmadu et al. (2018). Albumen height and yolk height were measured using vernier caliper after pouring the content of the egg in a petri dish.

\section{Statistical analysis of Data}


Data on egg quality characteristics were analysed using one way analysis of variance in a completely randomized design. Significant means were separated using Duncan's multiple range tests. In order to ensure that the data used for PCA is adequate, two tests were performed namely Kaiser Meyer Olkin (KMO) measure of sampling adequacy and Bartlett's test of sphericity. PCA was performed using the factor programme of SPSS 16 (2007).

\section{RESULTS AND DISCUSSION}

The external and internal egg quality characteristics of Bovan Nera, ISA Brown and FUNAAB Alpha from 35 to 45 weeks of age are presented in Table 1. Significant $(\mathrm{P}<0.05)$ differences were observed in some of the external and internal characteristics of eggs measured. ISA Brown produced significantly $(\mathrm{P}<0.05)$ the highest mean egg weight $(60.18 \mathrm{~g})$, followed by Bovan Nera (58.13g) and FUNAAB Alpha $(55.18 \mathrm{~g})$. Therefore, ISA Brown and Bovan Nera egg weights fall within the average weight of egg which is $58 \mathrm{~g}$ according to Shafey et al. (2014) while FUNAAB Alpha was below the average. FUNAAB Alpha layers may not have undergone the level of genetic improvement in egg production traits that ISA Brown and Bovan Nera had. Egg width, egg volume, egg surface area and albumen weight were similar in Bovan Nera and ISA brown but significantly $(\mathrm{P}<0.05)$ higher than FUNAAB Alpha. Albumen height and yolk height did not show significant difference
$(\mathrm{P}>0.05)$ among the three strains of chickens. Table 2 presents the phenotypic correlations among external and internal egg quality characteristics of Bovan Nera, ISA Brown and FUNAAB Alpha. A total of 45 correlations were computed among which 20, 28 and 20 were positively significant $(\mathrm{P}<0.05,0.01)$ in Bovan Nera, ISA Brown and FUNAAB Alpha respectively. The numbers of negative correlations were 3,3 and 2 in Bovan Nera, ISA Brown and FUNAAB Alpha accordingly. None of the negative correlations was significant $(\mathrm{P}>0.05)$ in the three strains. Highly significant $(\mathrm{P}<0.01)$ phenotypic correlations between and among egg weight and most of the traits were observed in the three strains of chickens. This implies high predictability among the egg quality traits. It also implies that an increase in any of the components associating with egg weight will lead to a corresponding increase in egg weight (Shaker and Aziz, 2017). Similar observation was made by Islam and Dutta (2010), Shafey et al. (2014) and Ukwu et al. (2014). The calculated values of KMO in Bovan Nera (0.66), ISA Brown (0.74) and FUNAAB Alpha (0.54) show that the sample size is adequate for PCA. Bartlett's test of sphericity obtained for Bovan Nera (Chi-square $=226.57$; $\mathrm{P}<0.01$ ), ISA Brown (Chi-square $=299.10$; $\mathrm{P}<0.01$ ) and FUNAAB Alpha (Chi-square = 450.83; $\mathrm{P}<0.01)$ were significant confirming that PCA was appropriate for the data. Tables 3 presents the communalities of the egg quality characteristics while Table 4 is the summary of principal component analysis showing the compo-

Table1. External and internal egg quality characteristics of three strains of layer type chickens at 35 to 45 weeks of age.

\begin{tabular}{llcc}
\hline External & Bovan Nera & ISA Brown & FUNAAB Alpha \\
\hline Egg weight $(\mathrm{g})$ & $58.1 \pm 0.66^{\mathrm{b}}$ & $60.3 \pm 0.71^{\mathrm{c}}$ & $55.2 \pm 0.89^{\mathrm{a}}$ \\
Egg length $(\mathrm{cm})$ & $4.08 \pm 0.03$ & $4.09 \pm 0.03$ & $4.10 \pm 0.03$ \\
Egg width $(\mathrm{cm})$ & $2.81 \pm 0.04^{\mathrm{b}}$ & $2.89 \pm 0.03^{\mathrm{b}}$ & $2.68 \pm 0.03^{\mathrm{a}}$ \\
Egg volume $(\mathrm{ml})$ & $53.8 \pm 0.76^{\mathrm{b}}$ & $53.9 \pm 0.67^{\mathrm{b}}$ & $51.7 \pm 0.83^{\mathrm{a}}$ \\
Egg surface area $(\mathrm{cm})$ & $35.4 \pm 0.56^{\mathrm{b}}$ & $36.2 \pm 0.70^{\mathrm{b}}$ & $33.7 \pm 0.48^{\mathrm{a}}$ \\
Internal & & & \\
Shell weight $(\mathrm{g})$ & $5.85 \pm 0.10^{\mathrm{ab}}$ & $6.11 \pm 0.13^{\mathrm{b}}$ & $5.58 \pm 0.08^{\mathrm{a}}$ \\
Albumen weight $(\mathrm{g})$ & $36.7 \pm 0.75^{\mathrm{b}}$ & $39.1 \pm 0.62^{\mathrm{b}}$ & $33.4 \pm 0.55^{\mathrm{a}}$ \\
Albumen height $(\mathrm{cm})$ & $0.89 \pm 0.02$ & $0.90 \pm 0.02$ & $0.86 \pm 0.01$ \\
Yolk weight $(\mathrm{g})$ & $13.9 \pm 0.22^{\mathrm{a}}$ & $14.5 \pm 0.20^{\mathrm{ab}}$ & $15.0 \pm 0.25^{\mathrm{b}}$ \\
Yolk height $(\mathrm{cm})$ & $1.70 \pm 0.02$ & $1.73 \pm 0.02$ & $1.72 \pm 0.02$ \\
\hline Mean values along the same row superscripted with different letters are significantly different $(\mathrm{p}<0.05)$.
\end{tabular}


Table 2: Phenotypic correlations among egg quality characteristics of three strains of layer chickens at 35 to 45 weeks of age

\begin{tabular}{|c|c|c|c|c|c|c|c|c|c|c|}
\hline Traits & EWT & ELT & EWTH & EVOL & ESURF & SWT & ALWT & ALHT & YWT & YHT \\
\hline \multicolumn{11}{|l|}{ Bovan } \\
\hline EWT & 1 & & & & & & & & & \\
\hline ELT & $0.64 * *$ & 1 & & & & & & & & \\
\hline EWTH & $0.34 *$ & 0.15 & 1 & & & & & & & \\
\hline EVOL & $0.60 * *$ & 0.27 & 0.13 & 1 & & & & & & \\
\hline ESURF & $0.68 * *$ & $0.58 * *$ & $0.77 * *$ & $0.30 *$ & 1 & & & & & \\
\hline SWT & $0.45 * *$ & $0.51 * *$ & 0.08 & 0.04 & 0.27 & 1 & & & & \\
\hline ALWT & $0.64 * *$ & $0.54 * *$ & $0.33 *$ & $0.39 * *$ & $0.59 * *$ & 0.22 & 1 & & & \\
\hline ALHT & 0.04 & $0.32 *$ & 0.04 & -0.08 & 0.18 & 0.25 & 0.14 & 1 & & \\
\hline YWT & $0.44 * *$ & $0.60 * *$ & -0.03 & 0.11 & 0.22 & $0.44 * *$ & 0.16 & 0.05 & 1 & \\
\hline YHT & 0.16 & $0.29 *$ & -0.10 & 0.06 & 0.07 & $0.29 *$ & 0.12 & 0.26 & 0.21 & 1 \\
\hline \multicolumn{11}{|l|}{ ISA B } \\
\hline EWT & 1 & & & & & & & & & \\
\hline ELT & $0.82 * *$ & 1 & & & & & & & & \\
\hline EWTH & $0.79 * *$ & $0.64 * *$ & 1 & & & & & & & \\
\hline EVOL & $0.37 *$ & 0.27 & 0.17 & 1 & & & & & & \\
\hline ESURF & $0.83 * *$ & $0.81 * *$ & $0.91 * *$ & 0.20 & 1 & & & & & \\
\hline SWT & $0.44 * *$ & $0.37 *$ & $0.36 *$ & -0.14 & $0.37 *$ & 1 & & & & \\
\hline ALWT & $0.64 * *$ & $0.49 * *$ & $0.55 * *$ & $0.35 *$ & $0.55 * *$ & 0.20 & 1 & & & \\
\hline ALHT & $0.33 *$ & 0.17 & $0.36^{*}$ & -0.12 & $0.30^{*}$ & 0.14 & 0.02 & 1 & & \\
\hline YWT & $0.51 * *$ & $0.44 * *$ & $0.36^{*}$ & $0.31 *$ & $0.41 * *$ & 0.05 & 0.13 & 0.06 & 1 & \\
\hline YHT & $0.41 * *$ & 0.22 & $0.44 * *$ & -0.08 & $0.36^{*}$ & 0.25 & 0.21 & $0.51 * *$ & 0.17 & 1 \\
\hline \multicolumn{11}{|l|}{ F Alph } \\
\hline EWT & 1 & & & & & & & & & \\
\hline ELT & $0.44 * *$ & 1 & & & & & & & & \\
\hline EWTH & $0.29 *$ & $0.30^{*}$ & 1 & & & & & & & \\
\hline EVOL & $0.37 *$ & $0.53 * *$ & $0.61 * *$ & 1 & & & & & & \\
\hline ESURF & $0.44 * *$ & $0.77 * *$ & $0.84 * *$ & $0.71 * *$ & 1 & & & & & \\
\hline SWT & $0.36^{*}$ & $0.31 *$ & 0.12 & 0.11 & 0.25 & 1 & & & & \\
\hline ALWT & $0.65^{* *}$ & $0.71 * *$ & $0.63 * *$ & $0.61 * *$ & $0.83 * *$ & 0.21 & 1 & & & \\
\hline ALHT & 0.14 & 0.10 & -0.04 & 0.16 & 0.04 & 0.03 & 0.03 & 1 & & \\
\hline YWT & $0.55 * *$ & 0.23 & 0.22 & $0.33 *$ & 0.26 & $0.29 *$ & 0.11 & 0.19 & 1 & \\
\hline YHT & $0.50 * *$ & 0.22 & -0.05 & 0.08 & 0.08 & 0.17 & 0.28 & 0.15 & $0.38 *$ & 1 \\
\hline
\end{tabular}

Values from 0.29 to 0.38 with single asterisks $(*)$ are significant at 0.05 levels while values from 0.39 to 0.99 with double asterisks $(* *)$ are significant at 0.01 levels. Bovan: Bovan Nera, ISA B: ISA Brown and F. Alph: FUNAAB Alpha, EWT: Egg weight, ELT: Egg length, EWTH: Egg width, EVOL: Egg volume, ESUR: Egg surface area, SWT: Shell weight, ALWT: Albumen weight, ALHT: Albumen height, YWT: Yolk weight, YHT= Yolk height.

nents extracted after varimax rotation, eigen value and percentage of total variance of egg quality traits of Bovan Nera, ISA Brown and FUNAAB Alpha. Communalities ranged from 0.40 to 0.90 in Bovan Nera, 0.57 to 0.92 in ISA Brown and 0.53 to 0.95 in FUNAAB Alpha respectively, thus indicating that greater proportions of the variance was shared in common by the variables (Khargharia et al., 2015). Three principal components (PC) each with eigen value greater than 1 were extracted after varimax rotation from the three strains. This explained $67.93 \%, 72.64 \%$ and $70.40 \%$ of the total phenotypic variance in Bovan Nera, ISA Brown and FUNAAB Alpha respectively. Goto et al. (2015) extracted five PCs from 22 egg quality traits from Onagadori and White leghorn breeds of chickens of Japan which explained $79.70 \%$ of the total phenotypic variance. Loading is the correlation between variables and principal components. PC1 loaded heavily on egg weight, egg width, egg surface area and albumen weight in Bovan Nera and egg weight, egg width, egg surface area, shell weight and albumen weight in ISA Brown. In FUNAAB Alpha, PC1 loaded heavily on egg length, egg width, egg volume, egg surface area and albumen weight. PC1 contributed $38.94 \%, 46.51 \%$ and $43.20 \%$ of the total variance in Bovan Nera, 
Table 3: Communality values of egg quality characteristics of three strains of chickens

\begin{tabular}{lllc}
\hline Traits & Bovan Nera & ISA Brown & FUNAAB Alpha \\
\hline EWT & 0.88 & 0.92 & 0.74 \\
ELT & 0.78 & 0.75 & 0.61 \\
EWTH & 0.81 & 0.80 & 0.72 \\
EVOL & 0.63 & 0.69 & 0.72 \\
ESURF & 0.90 & 0.86 & 0.95 \\
SWT & 0.56 & 0.69 & 0.53 \\
ALWT & 0.60 & 0.58 & 0.81 \\
ALHT & 0.64 & 0.75 & 0.79 \\
YWT & 0.60 & 0.57 & 0.56 \\
YHT & 0.41 & 0.67 & 0.61 \\
\hline
\end{tabular}

Table 4: Eigen values, total variance along with factor loadings after varimax rotations of egg quality characteristics of three strains of layer chickens

\begin{tabular}{llllllllll}
\hline & \multicolumn{3}{c}{ Bovan Nera } & \multicolumn{3}{c}{ ISA Brown } & \multicolumn{3}{c}{ FUNAAB Alpha } \\
\hline Traits & PC1 & PC2 & PC3 & PC1 & PC2 & PC3 & PC1 & PC2 & PC3 \\
\hline EWT & $\mathbf{0 . 5 8}$ & 0.49 & $\mathbf{0 . 5 5}$ & $\mathbf{0 . 8 7}$ & 0.29 & 0.28 & 0.40 & $\mathbf{0 . 7 6}$ & 0.01 \\
ELT & 0.41 & $\mathbf{0 . 7 6}$ & 0.16 & 0.32 & 0.12 & 0.21 & $\mathbf{0 . 7 0}$ & 0.35 & -0.06 \\
EWTH & $\mathbf{0 . 8 8}$ & -0.19 & -0.08 & $\mathbf{0 . 8 0}$ & 0.39 & 0.13 & $\mathbf{0 . 8 5}$ & -0.06 & -0.03 \\
EVOL & 0.28 & 0.12 & $\mathbf{0 . 7 3}$ & 0.26 & -0.26 & $\mathbf{0 . 7 4}$ & $\mathbf{0 . 8 1}$ & 0.11 & 0.25 \\
ESURF & $\mathbf{0 . 9 2}$ & 0.20 & 0.11 & $\mathbf{0 . 8 6}$ & 0.30 & 0.16 & $\mathbf{0 . 9 7}$ & 0.14 & -0.05 \\
SWT & 0.16 & $\mathbf{0 . 7 3}$ & -0.05 & $\mathbf{0 . 6 2}$ & 0.09 & 0.55 & 0.14 & $\mathbf{0 . 5 8}$ & -0.42 \\
ALWT & $\mathbf{0 . 6 5}$ & 0.29 & 0.31 & $\mathbf{0 . 7 4}$ & -0.11 & 0.15 & $\mathbf{0 . 8 5}$ & 0.29 & -0.09 \\
ALHT & 0.24 & 0.44 & -0.62 & 0.07 & $\mathbf{0 . 8 6}$ & -0.03 & 0.03 & 0.19 & $\mathbf{0 . 8 7}$ \\
YWT & -0.02 & $\mathbf{0 . 7 2}$ & 0.29 & 0.31 & 0.22 & $\mathbf{0 . 6 5}$ & 0.16 & $\mathbf{0 . 7 0}$ & 0.24 \\
YHT & -0.07 & $\mathbf{0 . 6 2}$ & -0.18 & 0.24 & $\mathbf{0 . 7 9}$ & -0.04 & -0.03 & $\mathbf{0 . 7 7}$ & 0.13 \\
Eigen & 3.89 & 1.71 & 1.19 & 4.65 & 1.59 & 1.02 & 4.32 & 1.68 & 1.04 \\
\% Var & 38.9 & 17.1 & 11.9 & 46.5 & 15.9 & 10.2 & 43.2 & 16.8 & 10.4 \\
\hline
\end{tabular}

Eigen: Eigen value, \%Var: Percentage of variance

ISA Brown and FUNAAB Alpha respectively. PC2 was characterized by egg length, shell weight, yolk weight and yolk height in Bovan Nera, albumen height and yolk height in ISA Brown and egg weight, shell weight, yolk weight and yolk height in FUNAAB Alpha. PC3 was strongly correlated with egg weight and egg volume in Bovan Nera, egg volume and yolk weight in ISA Brown and albumen height in FUNAAB Alpha. The variables strongly correlating with each PC differ among the three strains implying that their egg quality features differ genetically. However, the pattern of factor loadings show that PC1 was mostly correlated with egg width, egg surface area and albumen weight in the three strains of chicken. This shows that the egg quality features of the three strains of chicken were similar especially in the aforementioned traits. In addition, PC1 was also highly associated with egg weight in Bovan Nera and ISA Brown and with egg length and egg volume in FUNAAB
Alpha. Therefore, PC1 will be referred to as general egg width, egg surface area and albumen weight. At variance with the hypothetical meaning of PC1 in this study, Ahmadu et al. (2018) reported that egg quality traits associated with PC1 in their study were good indicators of general egg weight. Goto et al. (2015) reported that PC1 of Onagadori and White leghorn chickens loaded mostly on the sizes of the albumen and yolk, albumen and yolk weight.

\section{CONCLUSION}

The study has shown that FUNAAB Alpha was inferior to ISA Brown and Bovan Nera in egg weight, egg width, egg volume, egg surface area, shell weight and albumen weight from 35 to 45 weeks of age. Therefore, improvement of FUNAAB Alpha layers in egg quality traits is desirable in order to produce competitive eggs for the growing markets in Nigeria. PCA was used to 
condense 10 egg quality traits into 3 PCs in each strain. The PCs could be used effectively for selecting birds based on a group of variables that are related to each other.

\section{REFERENCES}

Abdullah, Sh. M and A. Shaker. 2018. Principal component analysis of internal egg traits for four genetic groups of local chicken. Egypt. Poult. Sci. 38 (11): 699-706.

Ahmadu, A., M. Kabir, A. O. Iyiola-Yunji, B. I. Nwagu, W. Buba and M. Y. Babe. 2018. Evaluation of egg quality traits of Shika Brown parents. J. Anim. Prod. 30 (1): 245-286.

Babajani, S., S. Alijani, M. Olyayee and A. Javanmard. 2018. Principal component analysis of internal egg quality and some performance traits of Azarbayjan native chickens. Res. Anim. Prod. 8 (17): 175. DOI:10.29252/rap.8.17.175.

Bjorklung, M. 2019. Be careful with your principal components. Evolution. 73: 2151 2158.

Desalew, T., E. Wondmech, G. Mekonnen and N. C. Rudra .2013. Genetic analysis of egg quality traits of exotic chickens in different production systems in East Shewa, Ethiopia. Afr. J. Agric. Res. 10: 10161021.

Goto, T., J. Shiraishi, T. Bungo and M.Tsudzuki. 2015. Characteristics of egg related traits in Onagadori (Japanese extremely long tail) breed of chickens. Japan. Poult. Sci. 52: 8187.

Hair, J. F., W. C. Black, B. J. Babin and R. E. Anderson .2009. Multivariate Data Analysis. $7^{\text {th }} \quad$ ed. Prentice Hall, Upper Saddle River, NJ.

Hanusova, E., C. Hrncar, A. Hanus and M.Oravcova .2015. Effect of breed on some parameters of egg quality in laying hens. Acta Fytotechn. Zootechn. 18: 20-24.

Khargharia, G., G. Kadirvel, S. Kumar, S. Doley, P. K. Bhari and Das, Mukut. 2015. Principal component analysis of morphological traits of Assam Hill goat in Eastern Himalayan India. J. Anim. Plant Sci. 25(5): 1251 1258.

Liu, Z., C. Sun, Y. Yan, G. Li, F. Shi, G. Wu, A. Liu and N. Yand .2018. Genetic variations of egg quality of chickens at late laying period revealed by genome wide association study. Sci. Rep. 8: 10832.

Monira, K. N., M. Salahuddin and G. Miah .2003. Effect of breed and holding period on egg quality characteristics of chicken. Int. J. Poult. Sci. Vol. 2: 261-263.

Saiful Islam, M and R. K. Dutta .2010. Egg quality traits of indigenous, exotic and crossbred chickens (Gallus domesticus L) in Rajashahi. Bangl. J. Life Earth Sci. 5: 6367.

Shafey, T. M., A. H. Mahmoud and M. A. Abouheif .2014. Dealing with multicollinearity in predicting egg components from egg weight and egg dimension. Italian J. Anim. Sci. 13: 4, 3408. Shaker, A. S and S. R. Aziz .2017. Internal traits of eggs and their relationships to shank feathering in chicken using principal component analysis. Poult. Sci. J. 5(1): 1- 5.

SPSS .2007. Statistics for social sciences, version 16.

Ukwu, H. O., P. O. Abari and D. J. Kuusu .2017. Principal component analysis of egg quality characteristics of ISA Brown layer chickens in Nigeria. World Sci. News 70(2): $304-$ 311.6

Venturini, G. C., R. P. Savegnago, B. N. Nunes, M. C. Ledur, G. S. Schmidt, L. E. Faro and D. P. Munari. 2013. Genetic parameters and principal component analysis for egg production from White Leghorn hens. Poult. Sci. 92: 2283-2289. 